\title{
PENGARUH BISNIS E-COMMERCE DAN PEMERIKSAAN PAJAK TERHADAP PENERIMAAN PAJAK (STUDI KASUS WAJIB PAJAK YANG TERDAFTAR DI KPP KELAPA GADING)
}

\author{
BAGUS APRILIANTO, ANGGA HIDAYAT \\ Prodi Akuntansi S1, Fakultas Ekonomi, Universitas Pamulang \\ angga1203hidayat@gmail.com
}

\begin{abstract}
This study aims to determine the effect of e-commerce business and tax audits on tax revenue at the Kelapa Gading Tax Office. The variables that are the focus of this research are E-Commerce Business $\left(X_{1}\right)$, Tax Examination $\left(X_{2}\right)$ as Independent Variables, and Tax Revenue $(Y)$ as Dependent Variables. This research was conducted through filling out the questionnaire by respondent. Samples were taken as many as 100 respondents, for the method of analysis and hypothesis using multiple linear regression, then the calculation uses the IBM SPSS Version 25 program, while the determination of the sample is done using the random sampling method. The results of this study indicate that the E-Commerce Business Variable has no effect on Tax Revenue. Meanwhile, the Tax Examination Variable affects Tax Revenue. Together (simultaneous) E-Commerce Business Variables and Tax Examination affect Tax Revenue. This is evidenced by a statistical test that is the calculation of the $F_{\text {count }}$ value of 22,913 with a significant level of 0,000.
\end{abstract}

Keywords: E-Commerce, Tax Audits and Tax Revenue

\section{PENDAHULUAN}

Meningkatnya perkembangan transaksi E-Commerce di Indonesia telah menjadi perhatian pemerintah untuk mulai mengatur aspek perpajakan transaksi E-Commerce dalam rangka optimalisasi penerimaan pajak di masa mendatang (Rendy \& Irawati, 2019). Kita perlu ketahui, pajak merupakan sumber utama penerimaan negara. Tanpa pajak sebagian besar kegiatan negara akan sulit untuk dapat dilaksanakan. Pendapatan negara yang salah satunya dari pajak inilah yang nantinya digunakan pemerintah untuk mewujudkan tujuannya yaitu mewujudkan masyarakat adil dan makmur. Perwujudan dari pendapatan ini digunakan pemerintah untuk membiayai program pembangunan di segala bidang yang akan dilaksanakan secara bertahap dan kepentingan masyarakat secara keseluruhan. Program pembangunan tersebut memerlukan dana dan biaya yang cukup besar, di mana sumber dana dan pembiayaannya diperoleh dari APBN. 
Seiring perkembangan zaman, eksistensi pajak berhadapan dengan berkembangnya teknologi informasi dan komunikasi yang semakin berkembang pesat. Kebutuhan hidup masyarakat yang semakin tinggi menimbulkan pemikiran masyarakat untuk berbisnis dan berusaha agar memiliki penghasilan untuk memenuhi kebutuhan hidup mereka. Di era modern saat ini bisnispun dapat dilakukan melalui media internet seperti online shop atau disebut dengan istilah transaksi E-Commerce (Rendy \& Irawati, 2019).

Pengusaha e-commerce sekarang tidak bisa lagi mengelak dari pajak. Direktorat Jenderal Pajak (DJP) Kementerian Keuangan mengungkapkan sudah menyelesaikan draf revisi Nomor 36 Tahun 2008 tentang Perubahan Keempat atas UU Nomor 7 Tahun 1983 tentang Pajak Penghasilan E-Commerce (PPh). Belum lagi penegasan dari Surat Edaran Direktorat Jenderal Pajak dalam Surat Edaran Nomor SE/62/PJ/2013 yang menyebutkan tidak ada pajak baru dalam transaksi $e$ commerce. Artinya, tidak ada perbedaan dalam penerapan peraturan perundangundangan perpajakan antara transaksi e-commerce dengan konvensional. Oleh karena itu, baik penjual maupun pembeli dapat dikenakan pajak sesuai dengan ketentuan perundang-undangan perpajakan yang sudah ada (Hidayat \& Yuliah, 2018). Para pelaku e-commerce tetap harus menghitung pajak mereka, menyetor serta melaporkan pajak, dan membuat e-Faktur bila sudah dikukuhkan menjadi Pengusaha Kena Pajak melalui aplikasi e-Faktur versi 2.0.

Penerimaan pajak sesuai dengan yang telah ditargetkan dapat tercapai apabila Wajib Pajak mau memenuhi kewajiban perpajakannya (Sugiyarti, 2017). Undang-Undang Nomor 28 Tahun 2007 Tentang Ketentuan Umum Dan Tata Cara Perpajakan pada pasal 1 ayat 2, menyebutkan bahwa wajib pajak merupakan orang pribadi atau badan, meliputi pembayar pajak, pemotong pajak, dan pemungut pajak yang mempunyai hak dan kewajiban perpajakan sesuai dengan ketentuan peraturan perundang-undangan perpajakan (Rosharlianti \& Hidayat, 2019).

Terciptanya jaringan komputer (terutama internet) telah memberikan peran yang sangat besar di dalam memudahkan hubungan antar para pengguna komputer di seluruh dunia (Hidayat, 2019). Hubungan dalam bentuk komunikasi dan pertukaran data bisa terjadi setiap saat. Adanya interaksi ini kemudian memunculkan inovasi untuk mengalihkan kegiatan di dunia nyata ke dalam dunia internet, salah satunya adalah kegiatan ekonomi. Hal inilah yang memunculkan bentuk lain dari transaksi konvensional ke dalam bentuk transaksi digital, yaitu $E$ -

Commerce. E- Commerce, didefinisikan sebagai transaksi pembelian dan penjualan barang atau jasa secara fisik menggunakan peralatan komunikasi elektronik, seperti telepon, komputer pribadi, online kiosk, Automatic Teller Machine (ATM), smart card atau smart phone (Nursyirwan, Ardaninggar, Septiningrum, Gustiasari \& Hasan, 2019).

Perdagangan elektronik memang cukup memberikan keuntungan baik bagi penjual maupun para pembeli sehingga penggunaan internet dalam melakukan transaksi masih sangat diminati dan diprediksi akan menggantikan transaksi yang masih menggunakan pola konvensional yaitu transaksi di mana penjual dan pembeli saling berhadapan untuk pembayaran dan penyerahan barang. 
Berbagai penyedia (provider) terkait layanan akses internet dan telekomunikasi juga turut berperan. Sebut saja operator telekomunikasi yangmenyediakan akses komunikasi dan akses internet, sehingga pengguna komputer dan internet dapat dengan mudah melakukan transaksi online dari perangkat mobile (misalkan: handphone, smartphone, tablet) maupun komputer desktop dan komputer jinjing (notebook, netbook).

Dukungan lainnya juga muncul dari pihak bank (baik di dalam negeri maupun di luar negeri) dan penyedia layanan transaksi elektronik. Pihak-pihak ketiga ini membantu di dalam proses transaksi online yang terjadi antar pembelidan penjual online. Misalkan saja disaat proses pembayaran secara elektronik yang dilakukan konsumen terhadap tagihan jumlah biaya yang harus dibayar berdasarkan barang yang diambil pada toko online, dengan memanfaatkan layanan E-Banking milik suatu Bank.

Banyaknya pengguna internet di Indonesia menunjukkan potensi pasar sangat besar yang akan mempengaruhi munculnya berbagai peluang bisnis baru. Melihat peluang tersebut, para pelaku bisnis harus semakin giat untuk memajukan bisnisnya. Dengan demikian peran internet di tahun 2018 hingga saat ini sangat berpotensi dan sangat berpeluang strategis bagi pertumbuhan bisnis di Indonesia.

Salah satu bisnis yang memanfaatkan teknologi internet yaitu online shopping atau sering disebut olshop. Tatap muka antar penjual dan pembeli tidak langsung terjadi, tetapi secara online melalui perantara perangkat komputer maupun mobile beserta dengan aplikasi dan sistem operasi (Rendy \& Irawati, 2019). Saat ini jika seorang ingin berdagang atau mempromosikan barang dagangannya sampai keluar negeri, pedagang itu cukup membuat situs dan menampilkan barang dagangannya di halaman situsnya. Para calon pembeli yang ada di luar negeri dapat melihat barang yang ditawarkannya dan jika calon pembeli tertarik, maka dapat langsung memesan barang tersebut dengan menghubungi kontak yang ada di biodata situs tersebut. Tidak lagi diperlukan biaya yang besar untuk mengurus perizinan, biaya untuk mendirikan toko di luar negeri, sewa gedung, dan juga membayar upah pekerja. Para pihak dalam transaksi tidak perlu bertemu face to face cukup melalui peralatan komputer ataupun media telekomunikasi. Hal ini merupakan pertanda telah dimulainya era cyber dalam dunia bisnis.

Perkembangan bisnis online shopping di Indonesia mengalami peningkatan yang cukup baik. Berdasarkan riset Online Shopping Outlook 2015 yang dikeluarkan oleh BMI research mengungkapkan, peluang pertumbuhan pasar online masih sangat besar seiring dengan meningkatnya jumlah pengguna internet di Indonesia. Menurut riset dari BMI, pada tahun 2014 pengguna belanja online mencapai $24 \%$ dari jumlah pengguna internet di Indonesia. Riset tersebut dilakukan di 10 kota besar di Indonesia terhadap 1.213 orang dengan usia 18-45 tahun melalui metode phone survey. Badan Perencanaan Pembangunan Nasional (Bappenas) memprediksi pertumbuhan penduduk Indonesia pada tahun 2015 mencapai 255.461 .700 orang, sementara pertumbuhan pengguna internet pada tahun ini versi Asosiasi Penyelenggara Jasa Internet Indonesia (APJII) adalah sekitar 139 juta pengguna. 
Otoritas Pajak menegaskan bahwa implementasi Peraturan Menteri Keuangan (PMK) Nomor 210/PMK.10/2018 Tentang Perlakuan Perpajakan atas Transaksi Perdagangan melalui Sistem Elektronik bertujuan untuk menciptakan rasa keadilan atau level playing field antara pelaku usaha konvensional maupun pelaku usaha e-commerce. Latar belakangnya dari peraturan ini adalah suatu industri yang sedang berkembang harus diatur sehingga menimbulkan level playing field yang sama. PMK 210 merupakan turunan yang lebih rinci dari Peraturan Presiden (Perpres) Nomor 74 Tahun 2017 tentang Peta Jalan Sistem Perdagangan Nasional Berbasis Elektronik (Road Map e-Commerce) Tahun 20172019 yang mengatur masalah perijinan, masalah perpajakan, bagaimana mengembangkan, mendukung e-commerce, sekaligus memberi perlindungan kepada masyarakat. Dengan PMK [210] ini, sebenarnya aturan mainnya menjadi jelas. Untuk pelaku seperti apa, pelapaknya seperti apa sehingga tidak ada lagi keraguan bagi masyarakat untuk memasuki ekosistem seperti itu. PMK ini turunan dari situ [Perpres 74] yang mengatur mengenai perpajakannya. perlakuan perpajakan untuk e-commerce ini sama persis dengan yang konvensional. Tidak ada yang berbeda dalam hal tarif, objek dan subjek. PMK ini hanya penegasan saja.

\section{TINJAUAN PUSTAKA}

\subsection{Pengertian Wajib Pajak}

Dalam ketentuan Umum dan Tata Cara Perpajakan (UU No. 28 Tahun 2007), yakni: "Wajib Pajak adalah orang pribadi atau badan, meliputi pembayar pajak, pemotong pajak, dan pemungut pajak yang mempunyai hak dan kewajiban perpajakan sesuai dengan ketentuan peraturan perundang- undangan perpajakan”. Badan sendiri adalah "Badan usaha kesatuan yuridis (hukum), teknis, dan ekonomis yang bertujuan mencari laba atau keuntungan. Badan usaha seringkali disamakan dengan perusahaan, walaupun pada kenyataannya berbeda. Perbedaan utamanya, badan usaha adalah lembaga sementara perusahaan adalah tempat di mana badan usaha itu mengelola faktor-faktor produksi".

Suryarini dan Tarmudji (2012) menyatakan bahwa wajib pajak adalah orang pribadi atau badan yang menurut ketentuan peraturan perundang-undangan perpajakan ditentukan untuk melakukan kewajiban perpajakan, termasuk pemungut pajak dan pemotong pajak tertentu.

\subsection{Pengertian $\boldsymbol{E}$-Commerce}

Istilah e-commerce merupakan singkatan dari electronic commerce adalah penyebaran, pembelian, penjualan pemasaran barang, dan jasa melalui sistem elektronik, yang secara singkat dapat didefinisikan sebagai mekanisme transaksi jual dan beli dengan menggunakan fasilitas internet sebagai media komunikasi.

Perdagangan elektronik (electronic commerce, disingkat EC, atau e-commerce) mencangkup proses pembelian, penjualan, transfer, atau pertukaran produk, layanan atau informasi melalui jaringan komputer, termasuk internet (Rendy \& Irawati, 2019). 


\subsection{Mekanisme Transaksi E-Commerce}

mekanisme transaksi E-Commerce dimulai dengan adanya penawaran suatu produk tertentu oleh penjual (misal berada atau bertempat kedudukan di AS) disuatu situs melalui server yang berada di Indonesia. Apabila konsumen di Indonesia melakukan pembelian maka konsumen tersebut akan mengisi "order mail" yang disediakan oleh pihak penjual. Cara pembayaran yang dapat dilakukan oleh konsumen tersebut yaitu dengan :

1. Transaksi model ATM

2. Pembayaran langsung antara dua pihak yang bertransaksi tanpa perantara

3. Dengan perantara pihak

4. Micropayment (recehan), dan

5. Anonymous digital cash.

Apabila proses pembayaran tersebut telah diotorisasi, maka proses pengiriman dapat dilakukan. Cara pengiriman atas produknya, apakah barang berwujud (melalui pengiriman biasa), jasa, atau produk digital (melalui proses download).

\subsection{Pengertian Pemeriksaan Pajak}

Menurut Mardiasmo (2018:56) yaitu sebagai berikut :

"Pemeriksaan pajak adalah serangkaian kegiatan menghimpun dan mengolah data, keterangan dan atau bukti yang dilaksanakan secara objektif dan profesional berdasarkan suatu standar pemeriksaan untuk menguji kepatuhan pemenuhan kewajiban perpajakan dan atau untuk tujuan lain dalam rangka melaksanakan ketentuan peraturan perundang-undangan perpajakan".

Definisi pemeriksaan pajak menurut Siti Kurnia Rahayu (2013:245) menyatakan bahwa: "Pemeriksaan Pajak merupakan hal pengawasan pelaksanaan system Self Assessment System yang dilakukan oleh wajib pajak, harus berpegang teguh pada Undang-undang perpajakan".

Definisi Pemeriksaan pajak Menurut Suandy (2014: 203) yaitu :

"Serangkaian kegiatan mencari, mengumpulkan, mengolah data dan/atau keterangan lainnya untuk menguji kepatuhan pemenuhan kewajiban perpajakan dan untuk tujuan lain dalam rangka melaksanakan ketentuan peraturan perundangundangan perpajakan. Untuk melaksanakan upaya penegakan hukum salah satunya dengan tindakan pemeriksaan pajak, maka mutlak diperlukan tenaga pemeriksa pajak dalam kuantitas dan kualitas yang memadai. Sedangkan untuk mendapatkan jaminan mutu atas hasil kerja pemeriksaan selain diperlukan kuantitas dan kualitas yang memadai diperluakn juga prosedur pemeriksaan, ruang lingkup, norma, pelaksanaan dan produk dari pemeriksaan."

Definisi pemeriksaan dijelaskan pada Peraturan Menteri Keuangan tentang Tata Cara Pemeriksaan Pajak Pasal 1 ayat (2) yang berbunyi: "Pemeriksaan adalah serangkaian kegiatan menghimpun dan mengolah data, keterangan, daya/bukti yang dilaksanakan secara obyektif dan professional berdasarkan suatu standar pemeriksaan untuk menguji kepatuhan pemenuhan kewajiban perpajakan dan/atau untuk tujuan lain dalam rangka melaksanakan ketentuan peraturan perundang-undangan perpajakan."

Berdasarkan beberapa definisi diatas, penulis menyimpulkan bahwa : 
Pemeriksaan Pajak merupakan kegiatan yang dilakukan oleh petugas Direktorat Jendral Pajak mulai dari mencari, mengumpulkan, sampai mengolah data dan atau keterangan lainya dengan tujuan untuk menguji kepatuhan kepatuhan Wajib Pajak dalam memenuhi kewajiban perpajakannya berdasarkan ketentuan perundangundangan perpajakan.

\section{METODE PENELITIAN}

\subsection{Jenis Penelitian}

Penelitian ini menggunaan penelitian kuantitatif dengan pendekatan assosiatif. Menurut (Sugiyono, 2017) Metode kuantitatif adalah metode penelitian yang berlandaskan pada filsafat positivisme, digunakan untuk meneliti pada populasi dan sampel tertentu, pengumpulan data menggunakan instrumen penelitian, analisis data bersifat kuantitatif/statistik, dengan tujuan untuk menguji hipotesis yang diterapkan.

\subsection{Lokasi Penelitian}

Penelitian ini dilaksanakan pada KPP Pratama Jakarta Kelapa Gading, sebagai tempat sumber informasi untuk melakukan riset. Tempat penelitian dipilih dengan pertimbangan bahwa data dan informasi yang dibutuhkan dapat diperoleh.

\subsection{Populasi dan Sampel}

\subsubsection{Populasi}

Populasi sasaran dalam penelitian ini adalah seluruh wajib pajak yang datang ke KPP Pratama Jakarta Kelapa Gading.

\subsubsection{Sampel}

Sampel dalam penelitian ini diambil menggunakan probability sampling dengan teknik simple random sampling, yaitu pengambilan anggota sampel dari populasi yang dilakukan secara acak tanpa memperhatikan strata yang ada dalam populasi itu. Dalam penelitian digeneralisasikan atau disimpulkan, sehingga sampel yang digunakan harus representatif. Adapun sampel dalam penelitian ini adalah orang-orang wajib pajak yang ditemui oleh peneliti pada KPP Pratama Jakarta Kelapa Gading secara acak yang paham dan mengerti perihal bisnis $e$ commerce.

\subsection{Uji Asumsi Klasik}

\subsubsection{Uji Normalitas}

Uji normalitas bertujuan untuk menguji apakah dalam model regresi variabel pengganggu atau residual memiliki distribusi normal. Dalam penelitian ini, uji normalitas menggunakan grafik p-plot dan Kolmogorov-Smirnov (1Sampel K-S). Bila p-value > 0.05, maka data dinyatakan berdistribusi normal. Ghozali (2016:154)

\subsubsection{Uji Multikolinearitas}

Multikolinearitas dapat dilihat dari nilai tolerance dan Variance Inflation Factor (VIF). Suatu model regresi dapat dikatakan bebas multikolinieritas jika 
mempunyai nilai VIF kurang dari 10 , dan nilai tolerance tidak kurang dari 0,10 . Sebaliknya ada multikolinieritas apabila nilai tolerance $<0.10$ atau nilai VIF $>10$ (Ghozali, 2016).

\subsubsection{Uji Heteroskedastisitas}

Pada saat mendeteksi ada tidaknya heteroskedastisitas dapat ditentukan dengan melihat grafik Plot (Scatterplot) antara nilai prediksi variabel terikat (ZPRED) dengan residual (SRESID), dan dasar untuk menganalisa seperti di bawah ini :

1. Heteroskedastisitas diindikasikan telah terjadi jika ada pola tertentu (bergelombang, melebar kemudian menyempit).

2. Heteroskedastisitas tidak terjadi jika tidak ada pola serta titik yang menyebardi atas dan di bawah angka 0 pada sumbu $\mathrm{Y}$.

\subsection{Uji Analisis Regresi Berganda}

Uji regresi berganda untuk menguji ada tidaknya pengaruh antara dua atau lebih variabel bebas (independen) terhadap variabel terikat (dependen) dengan pengukuran interval atau rasio dalam satu persamaan linier (Ghozali, 2016). Model regresi linier berganda yang digunakan untuk menguji hipotesis tersebut adalah sebagai berikut :

$$
Y=a+\beta_{1} X_{1}+\beta_{2} X_{2}+e
$$

\subsection{Koefisien Determinasi (Adjusted $\boldsymbol{R}^{2}$ )}

Nilai koefisien determinasi adalah antara nol dan satu. Apabila pada suatu model nilai $\left(\mathrm{R}^{2}\right)$ kecil atau sedikit berarti kemampuan variabel-variabel independen dalam menjelaskan variasi variabel dependen amat terbatas. Sebaliknya, apabila Nilai $\left(\mathrm{R}^{2}\right)$ mendekati angka satu berarti variabel-variabel independen memberikan hampir semua informasi yang dibutuhkan untuk memprediksi variasi variabel dependen.

\section{ANALISIS DATA DAN DISKUSI}

\subsection{Statistik Deskriptif}

Ada tiga variabel yang digunakan dalam melakukan uji statistik deskriptif disini, diantaranya yaitu bisnis e-commerce, pemeriksaan pajak dan penerimaan pajak. Hasil ujinya dapat dilihat dalam tabel 1 di bawah ini:

Tabel 1: Hasil Uji Statistik Deskriptif

\begin{tabular}{|l|c|r|r|r|r|}
\hline & $\mathrm{N}$ & \multicolumn{1}{|c|}{ Minimum } & Maximum & Mean & $\begin{array}{c}\text { Std. } \\
\text { Deviation }\end{array}$ \\
\hline Bisnis_e_Commerce & 100 & 28 & 50 & 41.45 & 5.112 \\
Pemeriksaan_Pajak & 100 & 18 & 40 & 30.91 & 4.420 \\
Penerimaan_Pajak & 100 & 17 & 30 & 25.44 & 3.046 \\
Valid N (listwise) & 100 & & & \\
\hline
\end{tabular}

Sumber: Data Primer yang diolah dengan IBM SPSS Statistics 25, 2019.

Berdasarkan tabel 1 menjelaskan bahwa pada variabel sistem Bisnis $e$ Commerce jawaban minimum responden sebesar 28 dan maximum 50, dengan 
rata-rata total jawaban 41.45 dan standar deviasi sebesar 5.112. Variabel pemeriksaan Pajak jawaban minimum sebesar 18 dan maximum 40, dengan ratarata total jawaban 30.91 dan standar deviasi sebesar 4.420. Variabel Penerimaan Pajak jawaban minimum sebesar 17 dan maximum 30, dengan rata-rata total jawaban 25.44 dan standar deviasi sebesar 3.046.

\subsection{Uji Asumsi Klasik}

\subsubsection{Uji Normalitas}

Tabel 2: Hasil Uji Normalitas One-Sample Kolmogorov-Smirnov Test

Unstandar

dized

Residual

\begin{tabular}{lr}
\hline Test Statistic &, 073 \\
\hline Asymp. Sig. (2-tailed) &, $200^{c, d}$ \\
\hline
\end{tabular}

a. Test distribution is Normal.

b. Calculated from data.

c. Lilliefors Significance Correction.

d. This is a lower bound of the true significance.

Sumber: Data Primer yang diolah dengan IBM SPSS Statistics 25, 2019.

Pada tabel 2 menunjukkan bahwa nilai signifikansi Kolmogorov- Smirnov sebesar 0,200 lebih besar dari 0,05. Syarat lulus uji normalitas adalah nilai Asymp. Sig. (2-tailed) > 0,05. dengan demikian dapat disimpulkan bahwa model regresi memenuhi asumsi normalitas baik dari grafik P-Plot maupun KolmogorovSmirnov.

\subsubsection{Uji Multikolinearitas}

Tabel 3: Hasil Uji Multikolinearitas Collinearity Statistics

\begin{tabular}{llr|r}
\multirow{2}{*}{ Model } & & Tolerance & \multicolumn{2}{l}{ VIF } \\
\hline 1 & (Constant) & & \\
\cline { 2 - 4 } & Bisnis_E_Commerce &, 817 & 1,224 \\
\cline { 2 - 4 } & Pemeriksaan_Pajak &, 817 & 1,224 \\
\hline
\end{tabular}

a. Dependent Variable: Penerimaan_Pajak

Sumber: Data Primer yang diolah dengan IBM SPSS Statistics 25, 2019.

Berdasarkan tabel 3 di atas dapat dilihat bahwa nilai tolerance untuk Bisnis E-Commerce sebesar $0,817<10$ dan VIF sebesar $1,224<10$, kemudian nilai tolerance untuk Pemeriksaan Pajak sebesar 0,817 <10 dan VIF sebesar 1,224< 10. Maka dapat disimpulkan bahwa dalam model regresi tidak terjadi multikolonieritas antar variabel independen. 


\subsubsection{Uji Heteroskedastisitas}

Berdasarkan hasil pengamatan data, maka hasil scaterplot dapat dilihat pada gambar di bawah:

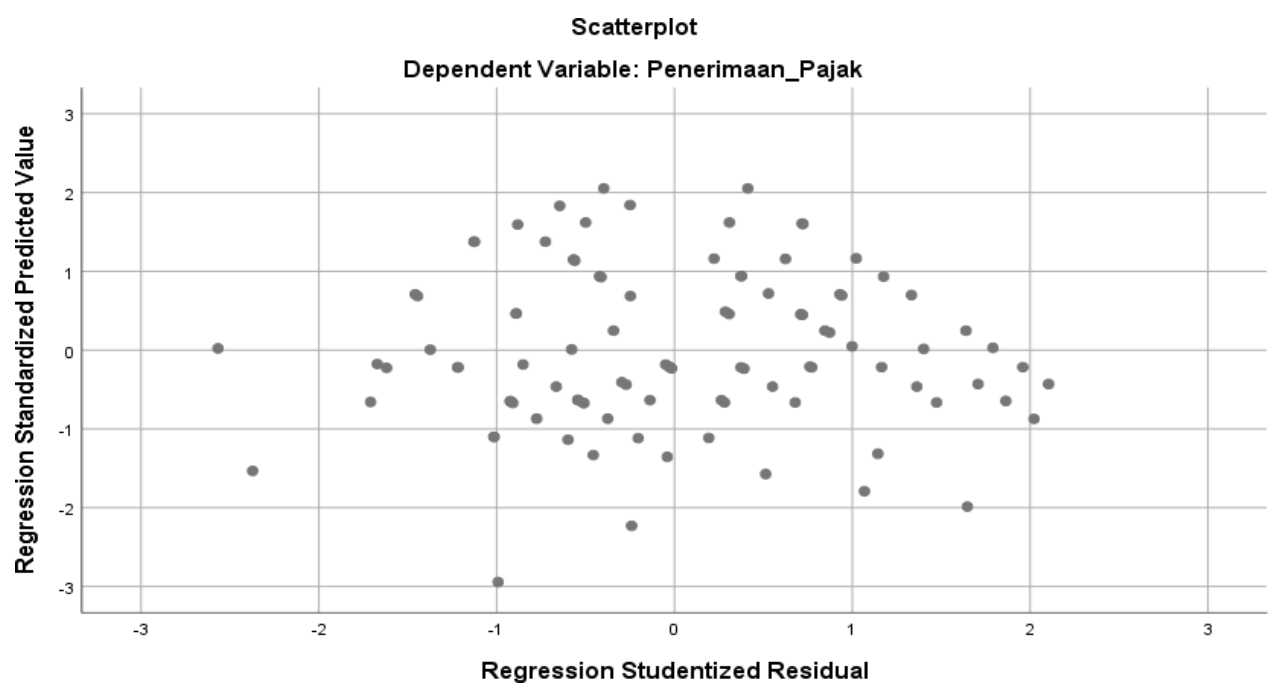

Sumber: Data Primer yang diolah dengan IBM SPSS Statistics 25, 2019.

Gambar 1: Hasil Uji Heteroskedastisitas

Dari gambar 1 di atas dapat diketahui bahwa scatterplot titik-titik menyebar secara acak, tidak membentuk pola yang jelas dan titik titik menyebar diatas dan dibawah angka 0 pada sumbu Y. Maka dapat disimpulkan bahwa tidak terjadi heteroskedastisitas dalam model regresi sehingga layak dipakai untuk memprediksi variabel Penerimaan Pajak. (Ghozali, 2016).

\subsection{Uji Regresi Berganda}

Tabel 4: Hasil regresi linear berganda

\begin{tabular}{|c|c|c|c|c|c|c|}
\hline \multirow[b]{2}{*}{ Model } & & \multicolumn{2}{|c|}{ Unstandardized Coefficients } & \multirow{2}{*}{$\begin{array}{l}\text { Standardized } \\
\text { Coefficients } \\
\text { Beta }\end{array}$} & \multirow[b]{2}{*}{$\mathrm{t}$} & \multirow[b]{2}{*}{ Sig. } \\
\hline & & $\mathrm{B}$ & Std. Error & & & \\
\hline \multirow[t]{3}{*}{1} & (Constant) & 13,226 & 2,308 & & 5,731 & 000 \\
\hline & Bisnis_E_Commerce & ,006 & ,055 & ,010 & , 103 & ,918 \\
\hline & Pemeriksaan_Pajak & ,388 & ,064 &, 562 & 6,075 & ,000 \\
\hline
\end{tabular}

a. Dependent Variable: Penerimaan_Pajak

Sumber: Data Primer yang diolah dengan IBM SPSS Statistics 25, 2019.

Sehingga dari hasil tersebut dapat disusun persamaan regresi linear berganda sebagai berikut: $\mathrm{Y}=13,226+0,006 \mathrm{X}_{1}+0,388 \mathrm{X}_{2}$ 


\title{
4.4. Uji Koefisien Determinasi (Adjusted $\mathbf{R}^{\mathbf{2}}$ )
}

\author{
Tabel 5: Uji Koefisien Determinasi (Adjusted $\mathbf{R}^{\mathbf{2}}$ )

\begin{tabular}{lrr|lr|l}
\multicolumn{2}{c|}{ Model Summary $^{\mathbf{b}}$} & & \multicolumn{2}{l}{$\begin{array}{l}\text { Adjusted } \\
\text { R Square }\end{array}$} & $\begin{array}{l}\text { Std. Error of } \\
\text { the Estimate }\end{array}$ \\
Model & R & R Square & & & \\
\hline 1 & &, $566^{\mathrm{a}}$ &, 321 &, 307 & 2,536 \\
\hline
\end{tabular} \\ a. Predictors: (Constant), Pemeriksaan_Pajak, Bisnis_E_Commerce \\ b. Dependent Variable: Penerimaan_Pajak \\ Sumber: Data Primer yang diolah dengan IBM SPSS Statistics 25, 2019.
}

Berdasarkan tabel 5 menunjukan bahwa besarnya koefisien determinasi (Adjusted $R$ Square) pada regresi sebesar 0,307 atau 30,7\%.

Dengan melihat hasil diatas, dapat disimpulkan bahwa variabel dependen dalam penelitian ini yaitu penerimaan pajak mampu dijelaskan atau dipengaruhi oleh variabel independen bisnis e-commerce dan pemeriksaan pajaksebagai variabel $30,7 \%$. Sedangkan sisanya $69,3 \%$ dipengaruhi oleh variabel-variabel lain yang tidak diteliti dalam penelitian ini.

\subsection{Uji Hipotesis}

\subsubsection{Uji Hipotesis Parsial (Uji t)}

\begin{tabular}{|c|c|c|c|c|c|}
\hline \multirow[b]{3}{*}{ Model } & \multicolumn{5}{|c|}{$\begin{array}{l}\text { Tabel 6: Hasil uji hipotesis analisis parsial (Uji t) } \\
\text { Coefficients }\end{array}$} \\
\hline & \multicolumn{2}{|c|}{$\begin{array}{l}\text { Unstandardized } \\
\text { Coefficients }\end{array}$} & \multirow[t]{2}{*}{$\begin{array}{l}\text { Standardized } \\
\text { Coefficients }\end{array}$} & \multirow[b]{2}{*}{$\mathrm{T}$} & \multirow[b]{2}{*}{ Sig. } \\
\hline & $\mathrm{B}$ & Std. Error & & & \\
\hline $1 \quad$ (Constant) & 13,226 & 2,308 & & 5,731 &, 000 \\
\hline Bisnis_E_Commerce & ,006 &, 055 & ,010 &, 103 & ,918 \\
\hline Pemeriksaan_Pajak & ,388 & ,064 &, 562 & 6,075 &, 000 \\
\hline
\end{tabular}

a. Dependent Variable: Penerimaan_Pajak

Sumber: Data Primer yang diolah dengan IBM SPSS Statistics 25, 2019.

Tabel 6 menunjukkan pengujian hipotesis yang dapat diuraikan sebagai berikut :

1. $\mathrm{H}_{1}$ : Bisnis E-Commerce tidak berpengaruh terhadap Penerimaan Pajak Berdasarkan tabel t menunjukkan bahwa nilai $t$ untuk variabel Bisnis $E$ Comerce memiliki $t_{\text {hitung }}$ sebesar 0,103 , lebih kecil dibanding nilai $t_{\text {tabel }} 1,985$ $(\alpha: 2 ; \mathrm{n}-\mathrm{k}-1=0,05: 2 ; 100-2-1=0,025 ; 97)$ atau $(0,103<1,985)$ dengan nilai signifikansi sebesar 0,918 yang artinya lebih besar dari alpha $(0,918>0,05)$. Hal ini mengindikasikan bahwa secara parsial variabel Bisnis E-Commerce tidak berpengaruh terhadap Penerimaan Pajak. Oleh karena itu, dapat disimpulkan bahwa $\mathrm{H}_{1}$ ditolak.

2. $\mathrm{H}_{2}$ : Pemeriksaan Pajak berpengaruh terhadap Penerimaan Pajak.

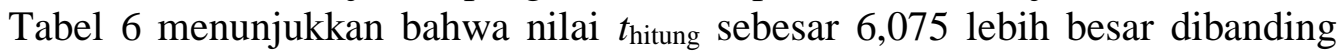
nilai $t \mathrm{t}_{\text {abel }} 1,985(\alpha: 2 ; \mathrm{n}-\mathrm{k}-1=0,05: 2 ; 100-2-1=0,025 ; 97)$ atau 
(6,075>1,985) dengan signifikansi 0,000 lebih kecil dari 0,05. Hal ini mengindikasikan bahwa secara parsial variabel Pemeriksaan Pajak tidak berpengaruh terhadap Penerimaan Pajak. Oleh karena itu, dapat disimpulkan bahwa $\mathrm{H}_{2}$ diterima.

\subsubsection{Uji Hipotesis Simultan (Uji F)}

Tabel 7: Hasil Uji Hipotesis Analisis Simultan (Uji F)

\begin{tabular}{|c|c|c|c|c|c|c|}
\hline \multicolumn{7}{|c|}{ Sum of $\quad$ ANOVA $^{\mathbf{a}}$} \\
\hline \multirow[t]{3}{*}{1} & Regression & 294,747 & 2 & 147,374 & 22,913 &, $000^{\mathrm{b}}$ \\
\hline & Residual & 623,893 & 97 & 6,432 & & \\
\hline & Total & 918,640 & 99 & & & \\
\hline
\end{tabular}

a. Dependent Variable: Penerimaan_Pajak

b. Predictors: (Constant), Pemeriksaan_Pajak, Bisnis_E_Commerce

Sumber: Data Primer yang diolah dengan IBM SPSS Statistics 25, 2019.

Berdasarkan tabel 7 di atas, menunjukkan bahwa nilai $F_{\text {hitung }}$ sebesar 22,913 dengan tingkat signifikan sebesar 0,000. Rumus untuk mencari $\mathrm{F}_{\text {tabel }}$ adalah (k-1 ; $\mathrm{n}-\mathrm{k})$ dengan jumlah sampel $(\mathrm{n})=100$, jumlah variabel $(\mathrm{k})=3$, taraf signifikan $\alpha=$ 0,05 , maka akan menghasilkan angka $(3-1 ; 100-3)=(2 ; 97)$, diperoleh nilai $F_{\text {tabel }}$ sebesar 3,090 sehingga dapat dikatakan bahwa nilai $\mathrm{F}_{\text {hitung }}$ lebih besar dari $\mathrm{F}_{\text {tabel }}$ yakni 22,913 > 3,090 dengan tingkat signifikansi 0,000<0,05. Dengan demikian maka dapat disimpulkan bahwa $\mathrm{H}_{3}$ diterima, yang menyatakan bahwa secara simultan variabel Bisnis E-Commerce $\left(\mathrm{X}_{1}\right)$, dan pemeriksaan pajak $\left(\mathrm{X}_{2}\right)$ berpengaruh terhadap Penerimaan pajak (Y).

\section{KESIMPULAN}

Berdasarkan hasil penelitian dan pembahasan mengenai pengaruh bisnis $e$ commerce dan pemeriksaan pajak terhadap penerimaan pajak pada Kantor Pelayanan Pajak Pratama Jakarta Kelapa Gading, Berdasarkan hasil analisis dan pengujian hipotesis yang telah dilakukan maka diperoleh kesimpulan sebagai berikut :

1. Variabel Bisnis E-Commerce tidak berpengaruh terhadap Penerimaan Pajak. Hal ini dibuktikan dengan uji statistik yaitu perhitungan $t_{\text {hitung }}$ sebesar $0,103<t_{\text {tabel }} 1,985$ dengan tingkat signifikansi sebesar 0,918 yang artinya lebih besar dari alpha $(0,918>0,05)$. Hal ini berarti $\mathrm{H}_{1}$ ditolak.

2. Variabel Pemeriksaan Pajak berpengaruh terhadap Penerimaan Pajak. Hal ini dibuktikan dengan uji statistik yaitu perhitungan $t_{\text {hitung }}$ sebesar $6,075>t_{\text {tabel }} 1,985$ dengan signifikansi 0,000 lebih kecil dari 0,05. Hal ini berarti $\mathrm{H}_{2}$ diterima.

3. Variabel Bisnis E-Commerce dan Pemeriksaan Pajak berpengaruh terhadap Penerimaan Pajak. Hal ini dibuktikan dengan uji statistik yaitu perhitungan nilai $F_{\text {hitung }}$ sebesar 22,913 dengan tingkat signifikan sebesar 0,000. Dengan demikian maka dapat disimpulkan bahwa $\mathrm{H}_{3}$ diterima. 


\section{Saran}

Berdasarkan kesimpulan di atas, penelitian ini di masa mendatang diharapkan dapat menyajikan hasil penelitian yang lebih berkualitas lagi dengan adanya beberapa masukan mengenai beberapa hal di antaranya:

1. Untuk penelitian selanjutnya disarankan untuk menggunakan teknik pengumpulan data metode survei dengan wawancara kepada responden. Sehingga akan mudah untuk mengendalikan responden yang berakibat responden menjawab pertanyaan sesuai dengan kenyataan.

2. Penelitian selanjutnya disarankan untuk memperluas wilayah cakupan penelitian sehingga hasil penelitian dapat digeneralisasikan untuk seluruh Kantor Pelayanan Pajak Pratama seluruh Indonesia.

3. Untuk penelitian selanjutnya disarankan untuk memperluas cakupan responden penelitian, dalam hal ini responden penelitian tidak hanya dari pihak wajib pajak melainkan juga dari pihak fiskus pajak. sehingga hasil penelitian dapat digeneralisasikan untuk seluruh Kantor Pelayanan Pajak Pratama seluruh Indonesia.

4. Untuk penelitian selanjutnya disarankan untuk menambahkan variabel independen lain untuk mengukur penerimaan pajak yang dilakukan oleh Wajib Pajak, seperti sanksi perpajakan.

\section{DAFTAR PUSTAKA}

Ghozali, I. (2016). Aplikasi Analisis Multivariate dengan Program IBM SPSS 23 Edisi 8. Semarang: BadanPenerbit Universitas Diponegoro.

Hidayat, A., \& Yuliah, N. (2018). The Effect of Good Corporate Governance and Tax planning on Company Value. EAJ (Economics and Accounting Journal), 1(3), 234-241.

Hidayat, A. (2019). Student's Self-Concept Profiles in Problem Posing According to Cognitive Styles: Developing An Evidence Base for Best Practice of ELearning in Mathematical Economics Course at Pamulang University. Jurnal Saintika Unpam: Jurnal Sains Dan Matematika Unpam, 1(2), 158-165.

Mardiasmo. (2018). Perpajakan. Yogyakarta: Andi

Nursyirwan, V. I., Ardaninggar, S. S., Septiningrum, L. D., Gustiasari, D. R., \& Hasan, J. M. H. (2019). Peningkatan Volume Penjualan Melalui Pelatihan Materi Dan Praktik Digital Marketing Bagi Para Pelaku Usaha Kecil Mikro-Pertanian Kota Depok (UKM-P). Abdimisi, 1(1), 24-30.

Rahayu, S. K. (2010). Perpajakan Indonesia Konsep dan Aspek Formal. Yogyakarta: Graha Ilmu

Rendy, R., \& Irawati, W. (2019). Understanding Of Tax Rules, Tax Tariffs and Tax-Rights Consciousness on E-Commerce Users Tax Compliance. EAJ (Economics And Accounting Journal), 2(2), 141-148.

Rosharlianti, Z., \& Hidayat, R. (2019). The Effect of Tax Planning and Deferred Tax Liabilities on Earns Management. EAJ (Economics And Accounting 
Journal), 2(2), 124-132.

Suandy, E. (2014). Hukum Pajak Edisi 6. Jakarta: Salemba Empat.

Sugiyono. (2017). Metode penelitian kuantitatif, kualitatif dan $R \& B$. Bandung : Alfabeta.

Sugiyarti, L. (2017). Analisis Pengaruh Struktur, Prosedur dan Strategi Organisasi dalam Reformasi Perpajakan terhadap Kepatuhan Wajib Pajak. Jurnal Ilmiah Akuntansi Universitas Pamulang, 5(1).

Suryarini, T. \& Tarmudji, T. (2012). Perpajakan di Indonesia. Yogyakarta: Graha Ilmu. 